\title{
Thermodynamic effect on a cavitating inducer in liquid hydrogen
}

\author{
Eric Goncalvès * Regiane Fortes Patella \\ LEGI - Grenoble INP \\ Julien Rolland, Benoit Pouffary \\ Guillaume Challier \\ CNES, Evry, France \\ Snecma, Vernon, France
}

\begin{abstract}
This study was led in collaboration with the French space agency (CNES) and the rocket engine division of Snecma. The main aims were the simulations and the analyses of cavitating flows in the rocket engine turbopump inducers, where the operating fluids are LH2 and LOx under cryogenic conditions.

A $\rho(P, T)$ state law modeling the cavitation phenomenon was integrated by the laboratory LEGI in the commercial CFD code Fine/Turbo ${ }^{T M}$, developed by Numeca International. Various $3 D$ numerical results are given for an inducer geometry and comparisons are made with experimental data (head drop curves) obtained by NASA.
\end{abstract}

\section{Nomenclature}

$\Psi=\frac{P_{t o t}^{\text {outlet }}-P_{\text {tot }}^{\text {inlet }}}{\rho_{L} U_{r e f}^{2}}$ the shroud head coefficient.

$\mathrm{NPSH}=\frac{P^{\text {inlet }}-P_{\text {vap }}\left(T_{\text {ref }}\right)}{\rho_{L} g} \quad$ the net positive suction head.

*Corresponding author: Address: LEGI, Domaine Universitaire, 38400 St Martin d'Heres, France; phone: 33-4-76825196; fax: 33-4-76827022; e-mail:eric.goncalves@legi.grenoble-inp.fr 
$\phi=\frac{U_{\text {ref }}}{\omega R_{\text {shroud }}} \quad$ the flow rate coefficient.

$\alpha$ the void ratio.

$E c=\frac{R^{2} \omega^{2}}{L_{v a p}\left(T_{r e f}\right)} \quad$ the Eckert number.

\section{Introduction}

The simulation and the prediction of cavitation in cryogenic fluids is of critical importance for the efficient design and performance of turbopumps in rocket propulsion systems. In temperature sensitive fluids as LH2 and LOx, thermal effects and strong variations in fluid properties are observed, which alter the cavity characteristics.

For cryogenic fluids, the liquid-vapor density ratio is lower than in cold water and consequently more liquid mass has to vaporize to sustain a cavity. Therefore evaporative cooling effects are more pronounced and the temperature of the liquid in the immediate vicinity of the liquid-vapor interface is depressed below the free-stream temperature. Because of the strong variation of thermodynamic properties (mainly the vapor pressure), the temperature depression, negligible in water, is quite substantial. The local cooling effect delays the cavitation phenomenon and reduces the local vapor pressure of the fluid, which leads to a lower observed cavity pressure. Typically this results in improved mean performance of cryogenic pumps.

First studies about thermal effects were generally focussed on obtaining correlations for temperature depression as a function of flow conditions and liquid properties. Particular methods of importance include the $B$-factor theory $[11,16,21]$ to characterize the sensitivity 
of fluids to thermodynamic effects, and the entrainment theory $[1,10]$. The $B$-factor method is based on the ratio of vapor volume to liquid volume affected by the vaporization process. A simple heat balance between the two phases can estimate the scale of temperature difference $\Delta T^{*}$ caused by thermal effects. The $B$-factor is estimated as the ratio between the actual temperature drop $\Delta T$ and $\Delta T^{*}$ :

$$
\Delta T^{*}=\frac{\rho_{V} L_{v a p}}{\rho_{L} C_{p_{L}}} \quad \text { and } \quad B=\frac{\Delta T}{\Delta T^{*}}
$$

where $L_{v a p}$ is the latent heat, $\rho_{L}$ and $\rho_{V}$ densities for the liquid and vapor phases, respectively. $C_{p_{L}}$ represents the specific heat.

Some numerical models have been developed to investigate thermodynamic effects in cavitating flows with one-fluid method. The one-fluid method treats the cavitating flows as a mixture of two fluids behaving as one. The governing equations are composed by three conservation laws written for the mixture. These models are based on the assumption of local kinematic equilibrium between phases (the local velocity is the same for both phases) and local thermodynamic equilibrium between the two components (local temperature and pressure equality between phases). This Homogeneous Equilibrium Model (HEM) cannot reproduce strong thermodynamic or kinetic non-equilibrium effects but, due to its simplicity, it has often been used for the numerical simulation. Different equations of state (EOS) have been used to define the thermodynamic behavior of the mixture to simulate cavitation: in liquid hydrogen [2], in warm water [18], in freon R-114 [6, 19] and in octane [4].

A four-equation model, very popular to simulate cavitating flows in water, has been used in cryogenic applications $[12,13,22,25]$. It is obtained by adding a mass equation for the 
vapor or liquid density including a cavitation source term. The main difficulty is related to the formulation of the source term and the tunable parameters involved for the vaporization and condensation process (different sets of parameters are presented in [22]).

This paper proposes an equation of state based on a modified barotropic law to model the mass and heat transfer exchanges. In the following, we first summarize the essential elements of the governing equations, the modeling concepts and the numerical methods, then present the three-dimensional results on an inducer.

\section{Models and numerics}

\subsection{Equations and models}

The solver is based on the compressible Reynolds-averaged Navier-Stokes equations, expressed in a relative frame of reference. Cavitation is modeled through a single fluid approach with a $\rho(P, T)$ equation of state. In the cavitation region, the liquid-vapor mixture is described with its averaged density, velocity and pressure. The density is assumed to be constant in the pure phases, while in the mixture region, it is directly linked to the pressure and the temperature with the EOS. The temperature $T$ is computed with the total energy equation and constant thermal capacities. The EOS is based on a barotropic law, proposed by Delannoy and Kueny for cold water [3], modified by introducing thermal dependency of vapour pressure [20]:

$$
\rho(P, T)=\frac{\rho_{L}+\rho_{V}}{2}+\frac{\rho_{L}-\rho_{V}}{2} \sin \left(\frac{P-P_{v a p}(T)}{c_{\text {baro }}^{2} \frac{\rho_{L}-\rho_{V}}{2}}\right)
$$


This law is characterized by its maximum slope $1 / c_{\text {baro }}^{2}$, where the velocity $c_{\text {baro }}$ is a tunable parameter. It is fixed to $1.75 \mathrm{~m} / \mathrm{s}$ in this study. Different values have been tested, up to 6 $\mathrm{m} / \mathrm{s}$, the influence on the head coefficient was weak.

\section{$2.2 \quad$ Numerical methods}

The cavitation model has been implemented in the Fine/Turbo ${ }^{T M}$ solver by Rolland [20]. This code is based on a cell-centered finite-volume discretization for multi-domain structured meshes [5].

For the mean flow, the convective flux density is computed with the space-centered Jameson scheme stabilized with scalar artificial dissipation [14]. The diffusive flux density is computed with a second-order space-centered scheme.

A well-known problem concerns the stiffness on the solution convergence in incompressible areas. In this situation, the dominance of convection terms renders the system stiff and compressible solvers converge slowly. To overcome this difficulty, a preconditioned method is necessary. The physical acoustic waves are replaced by pseudo-acoustic modes that are much closer to the advective velocity, reducing the stiffness and enhancing the convergence. The preconditioned method developped by Hakimi [8] is used.

The code marches the solution in time to steady state, using an explicit 4 step Runge- 
Kutta algorithm. The convergence is enhanced through local time stepping, implicit residual smoothing and multigrid acceleration techniques (for non cavitating computations).

\subsection{Turbulence model}

The Yang-Shih $k-\varepsilon$ model [24] with two-layer wall functions [9] is used.

\subsection{Computation procedure to simulate head drop}

The cavitating behavior of the inducer is investigated through the technique described by Pouffary et al. [17] for cold water. The pump flow is first computed with incompressible liquid hydrogen. Then cavitation is progressively introduced by increasing the vapor pressure.

\section{Geometry and experimental conditions}

The tested geometry is a NASA three-bladed flat plate helical inducer (Figure 1) characterized by an angle of attack of $80.6^{\circ}$ and an infinite hub [15]. The fluid is liquid hydrogen in cryogenic conditions. The selected operating points are characterized by:

$R_{\text {shroud }}=0.063 \mathrm{~m}:$ the shroud radius

$\omega=30000 \mathrm{rpm}:$ the rotation velocity

$U_{\text {ref }}=\omega R_{\text {shroud }} \simeq 200 \mathrm{~m} / \mathrm{s}:$ the reference velocity

$T_{\text {ref }}=19 \mathrm{~K}$ and $23 \mathrm{~K}$ : the reference temperatures

$\phi=0.098$ and 0.108 : the flow rate coefficient

$R e=\frac{U_{\text {ref }} R_{\text {shroud }}}{\nu\left(T_{\text {ref }}\right)} \simeq 7.10^{7}:$ the Reynolds number based on the shroud radius 
An enlargement of the blade leading edge is shown in Figure 2, where the bevel is drawn. For this geometry, cavitation can appear along the bevel, on the leading edge and also on the trailing edge. Cavitation appears also at the back end of the bevel (the point $B$ ), which corresponds to the attachment point of sheets.

\section{Properties of liquid hydrogen}

The $L H 2$ is characterized by large variations of thermodynamics properties with the temperature (especially the vaporization pressure), as shown in Table 1. A change of temperature from $T_{r e f}=19 \mathrm{~K}$ to $T_{r e f}=23 \mathrm{~K}$ corresponds to a change in vapor pressure of a factor of three. Moreover, it increases also the $\Delta T^{*}$ value. As illustrated by the experimental results presented in Figure 4, the temperature has a major influence on the NPSH breakdown value.

\section{$5 \quad$ Mesh and boundary conditions}

The grid is a HOH-type topology. Only one blade-to-blade channel is considered. The mesh contains around 740000 nodes. The tip leakage is considered. The $y^{+}$values at the walls

vary between 0.5 and 100 . A view of the complete mesh is given in Figure 3.

Calculations are performed with the following boundary conditions. The mass flow is imposed at the inlet, and the static pressure is imposed at the outlet. The hub and the blades are rotating, the shroud is immobile. Wall functions are imposed along solid boundaries, assumed to be adiabatic. 


\section{$6 \quad$ Results and analyses}

For this geometry, according to non cavitating numerical results, the flow rate corresponding to the best hydraulic efficiency of the pump is about $\phi=0.1$. The two studied flow rates, $\phi=0.098$ and $\phi=0.108$, are respectively lower and higher. For the second flow rate, the angle of attack of fluid is negative, which induces also the development of cavitation in the pressure side of the blade.

\subsection{Head drop curve}

Figure 4 illustrates head drop curves $\Psi(N P S H)$ for both flow conditions. From experimental data analyses, one can observe that the NPSH breakdown value for $T_{r e f}=23 \mathrm{~K}$ is smaller than one corresponding to $T_{r e f}=19 \mathrm{~K}$ (even if the flow rate is less important for $19 \mathrm{~K}$ tests). This behaviour is related to the thermodynamic properties of the liquid hydrogen (see Table 1). In this table, we introduced a characteristic difference of pressure $\Delta P^{*}$ defined as:

$$
\Delta P^{*}=\Delta T^{*} \frac{d P_{v a p}}{d T}
$$

Both characteristic differences $\Delta T^{*}$ and $\Delta P^{*}$ are higher for $L H_{2}$ at $T_{r e f}=23 \mathrm{~K}$. During the cavitation process, the local cooling down and $P_{\text {vap }}$ variations are more relevant at this temperature. These thermodynamic effects delay the cavitation phenomenon.

To deep the analyses, it is interesting to evaluate also the dimensionless pressure gradient $\rho_{L} U_{r e f}^{2} / \Delta P^{*}$ (see Table 2), which is higher for $T_{r e f}=19 \mathrm{~K}$. This parameter relates the flow inertial characteristics to the vaporization rate. Indeed, in this global analysis, we consider that depressions related to the streamline curves are proportional to $\rho_{L} U_{\text {ref }}^{2}$, and that this 
term promotes the vaporization process.

Preliminary validations of the numerical and physical models have been carried out by comparisons between calculated head drop curves $\Psi(N P S H)$ and measured ones (Figure 4). For the operating point $\left(\phi=0.098, T_{r e f}=19 \mathrm{~K}\right)$, the performance breakdown is well predicted. The error on the NPSH breakdown value is only 1.5\%. We observe, in the experimental data, a zone of large variations of $\Psi$, for NPSH values between 40 and $80 \mathrm{~m}$. This behavior is due to the development of cavitation instabilities, which are not captured by our steady computations.

For the other operating point $\left(\phi=0.108, T_{r e f}=23 \mathrm{~K}\right)$, the breakdown is more abrupt, with small variations in the instabilities zone. The numerical performance breakdown is not so close to the experimental data, the error is around $22 \%$. This inaccuracy is the same order of one obtained in [7] for a cold water inducer.

The physical analyses proposed here below will be based on numerical results obtained for $T_{r e f}=23 \mathrm{~K}$, because the thermodynamic effects is more important than the one at $T_{r e f}=19 \mathrm{~K}$.

\subsection{Visualization of the vapor/liquid structures}

The computed mixture vapor/liquid structures are presented in Figure 5, during the NPSH decrease, for the operating point $\left(\phi=0.108, T_{r e f}=23 \mathrm{~K}\right)$. 
For NPSH=108m (top of the figure), a small cavity sheet appears on the leading edge bevel, near the shroud, and also an attached cavity from the point B (see Figure 2). When the NPSH value decreases, the small cavity on the bevel reduces whereas the principal cavity grows and detached from the suction side. Finally, for NPSH=30m, a large cavity reaches the throat of the channel.

\subsection{Void ratio and temperature distributions}

The void ratio and temperature distributions are studied in different cylindrical cutting planes, at constant radius (see Figure 6), presented in a blade-to-blade view, for the operating point $\left(\phi=0.108, T_{r e f}=23 \mathrm{~K}\right)$. This point is chosen because it corresponds to the strongest thermal effect.

\subsubsection{Mid-span cut}

The void ratio contours on a mid-span cutting plane are plotted in Figure 7 when the NPSH value decreases (from left to right). We observe a short cavity on the suction side, attached after the end of the bevel, which grows substantially. The cavity sheet thickness is relatively important (in comparison with the other case $T_{r e f}=19 \mathrm{~K}$ ). The void ratio is lower than $30 \%$. We can see also a small cavity on the trailing edge bevel. The development of cavitation on the pressure side is clearly observed. When the NPSH decreases, the cavity sheet on the suction side reaches the throat, generates large blockage to the oncoming flow and the performance breaks down.

The temperature distribution on the same cutting plane, is showed in Figure 8. The 
temperature is well correlated to the void ratio, plotted in Figure 7 . The cooling effect due to the vaporization is evidenced. The cooling maximum value estimated with the reference temperature is about $1 \mathrm{~K}$.

\subsubsection{Near-shroud cut}

The void ratio contours on a cutting plane close to the shroud are plotted in Figure 9. In comparison with the mid-span contours, for high values of NPSH, the cavity sheets are thicker, the void ratio reaches $50 \%$, and we do not observe cavity sheets on the pressure side. Rapidly, an extended cavity interacts with the leading edge of the neighboring blade. For low values of NPSH $(\mathrm{NPSH}=30 \mathrm{~m})$, cavitation appears on the pressure side and the channel is completely obstructed. We observe small cavities on the trailing edge bevel, in which the maximum void ratio value is about $50 \%$. When the cavitation develops, we can see that the maximum void ratio value moves from the leading edge to the trailing edge.

Moreover, for this case with strong thermal effects, during the NPSH decrease, we can note that the void ratio first increases then decreases. When the cavity becomes larger, the void ratio and the temperature depression increase. Then, when the cavity reaches the throat section of the inducer, the void ratio and the temperature depression decrease slightly, which is probably due to the interaction between the cavity and the flow around the leading edge of the adjacent blade. This situation was also commented in [23].

To compare, the void ratio contours, in the same cutting plane, are presented in Figure 10 for the operating point $\left(\phi=0.098, T_{r e f}=19 \mathrm{~K}\right)$. For this point, thermal effects is less significant, therefore the void ratio is higher. Indeed, the maximum value is around $80 \%$. 
Small cavities appear on the pressure side (for $\mathrm{NPSH}=34 \mathrm{~m}$ ). For $\mathrm{NPSH}=27 \mathrm{~m}$, the cavity do not obstruct the channel. The performance breakdown is certainly due to the torque reduction.

The temperature contours close to the shroud, for the operating point $\left(\phi=0.108, T_{\text {ref }}\right.$ $=23 \mathrm{~K})$, are presented in Figure 11. The temperature is well correlated to the void ratio, as noticed previously. The location of the maximum temperature depression corresponds to the location to the maximum values of void ratio. We observe a heating effect along the blade, especially on the pressure side and at the end of the trailing edge. We interpret this phenomenon as a viscous warming effect along the wall. To study it, the wall temperature is analysed on the next section.

\subsection{Wall temperature}

The wall temperature on the suction side is plotted in Figure 12, for the operating point $\left(\phi=0.108, T_{r e f}=23 \mathrm{~K}\right)$. This figure shows the wall temperature in non cavitating regime (on the left) and in cavitating regime (on the right).

For the non cavitating flow, we observe a viscous warming effect on the wall, which increases with the radius. It is around $1.2 \mathrm{~K}$ close to the shroud, and it is on the same order of the temperature depression $\Delta T^{*}$. The same heating effect can be evidenced on the pressure side. 
For the cavitating regime, there is a "competition" between these two phenomena : the viscous heating effect versus the vaporization cooling effect. We can clearly see the thermal "footprint" of the cavity sheet, attached after the end of the leading edge bevel (dotted line). The lowest temperature is around $22 \mathrm{~K}$; it corresponds to a cooling effect, estimated with the reference temperature, between $0.5 \mathrm{~K}$ (hub) and $1 \mathrm{~K}$ (shroud). The absolute cooling value can reach $2 \mathrm{~K}$.

Due to the high rotation velocity, the Eckert number is high (about a factor 100 compared to an usual inducer in cold water) and the viscous heating becomes no more negligible. Values of Eckert and Mach numbers are presented in Table 2, for hub and shroud radii. Mainly close to the shroud, the Mach number is about 0.2 in the pure liquid, compressibility effects should be not influential.

Figure 13 shows the wall temperature, on the suction side, when the cavitation develops (from A to E), for the operating point $\left(\phi=0.108, T_{r e f}=23 \mathrm{~K}\right)$. The dotted line indicates the end of the leading edge bevel.

Figure 14 presents the wall temperature, on the pressure side, when the cavitation develops (from A to E). The dotted line indicates the end of the trailing edge bevel. We can observed the development of cavitation on this side. On the trailing edge, a small cavity sheet on the bevel appears when the NPSH value decreases.

For both figures 13 and 14 the thermal competition between a viscous heating and a 
vaporization cooling is evidenced.

Moreover, the wall temperature on the suction side is plotted in Figure 15, for the operating point $\left(\phi=0.098, T_{r e f}=19 \mathrm{~K}\right)$. This figure shows the wall temperature in non cavitating regime (on the left) and in cavitating regime (on the right). We observe the same thermal behaviour.

To evaluate the impact of the wall boundary conditions, we made computations with isothermal walls, $T_{\text {wall }}=23 \mathrm{~K}$, with a flow rate $\phi=0.108$. The wall heat transfer (wall to fluid) on the suction side is plotted in Figure 16. In non cavitating regime (on the left), the temperature of the fluid is greater than the imposed wall temperature, especially on the shroud area where the heat flux is the higher. In cavitating regime (on the right), the heat transfer becomes positive in the mixture area, the temperature of the fluid being smaller than 23K. Both heating and cooling effects are again evidenced.

To check this interesting result, especially regarding the grid used, a finer mesh has been built. The new grid is a HOH-type topology, which contains around 1457500 nodes. The $y^{+}$values at the walls are on the same order than the coarse grid. Views of the leading and trealing edges are given in Figure 17 for both meshes.

The selected operating point is $\phi=0.103$ and $T_{r e f}=22 \mathrm{~K}$, which is an intermediate value of previous operating points. Only two computations were performed because of the large CPU cost. Figure 18 shows the wall temperature on the suction side in non cavitating regime (on the left) and in cavitating regime (on the right). As previously, the opposition of a viscous 
heating effect and a vaporization cooling effect are clearly observed.

\section{Conclusions}

Only few numerical models allowing the 3D simulation of viscous cavitating flows under cryogenic conditions exist in the literature. In the present work, a new homogeneous onefluid cavitation model taking into account thermal effects was proposed and implemented in the Fine/Turbo ${ }^{T M}$ code. This original approach, based on a $\rho(P, T)$ state law, is an improvement of our previous works concerning a barotropic model and cold water applications $[7,17]$. In those studies, we have obtained a good prediction of the head drop charts for different pump geometries at several flow rates.

In the present paper, the studied application concerns $L H 2$ cavitating flows in a NASA inducer geometry, running at very high rotation velocity. The non cavitating and cavitating pump global performances (as the head drop charts) have been well estimated from numerical work, if compared to experimental results at two different running conditions. Comparative analyses of void ratio and temperature distributions have been proposed in the paper. From this initial study, an interesting result has been evidenced: at very high rotation velocity, viscous effects at the wall seem to be relevant and lead to a heating effect, mainly at the pump shroud. The observed heating is of the same order of cooling effect amplitude due to vaporization. The obtained cavitating flows near the solid boundaries result from a balance between these opposite phenomena. This behaviour, if it is verified, could have an important influence, for example, on the cavitation instabilities trigger. Further studies concerning 
other rotation velocities, grids, turbulence models and cavitating flow conditions are necessary to attest this result. Moreover, the physical model has to be improved to take into account temperature variations of thermal capacities and to better predict cavitation behavior. Moreover, further experimental works concerning local measurements in temperature sensitive fluid cavitation are capital to allow model calibration and validation.

\section{Acknowledgments}

The authors wish to express their gratitude to the French space agency CNES and to the SNECMA company to support this research. The authors wish also to express their gratitude to NUMECA International for its cooperation to the development of the numerical code.

\section{References}

[1] Billet, M.L., Holl, J.W., and Weir, D.S., 1981. "Correlations of thermodynamic effects for developped cavitation", Journal of Fluids Engineering 103(12):534-542.

[2] Cooper, P., 1967. "Analysis of single and two-phase flow in turbopump inducers", Journal of Engineering Power, 89:577-588.

[3] Delannoy, Y., and Kueny, J-L., 1990. "Two phase flow approach in unsteady cavitation modelling", Proceedings of Cavitation and Multiphase Flow Forum, ASME-FED, 98:153-158.

[4] Edwards, J.R., and Franklin, R.K., 2000. "Low-Diffusion Flux Splitting methods for real fluid flows with phase transition", AIAA Journal, 38(9):1624-1633. 
[5] Fine/Turbo ${ }^{T M}$, 2003. "Numerical Mechanics applications", Software package, Ver.4.0-1, Numeca International.

[6] Goncalvès, E., and Fortes Patella, R., 2010. "Numerical study of cavitating flows with thermodynamic effect", Computers \& Fluids, 39(1):99-113.

[7] Gonzalo Flores, N., Goncalves, E., Fortes Patella, R., Rolland, J., and Rebattet, C., 2008. "Head drop of spatial turbupump inducer", Journal of Fluids Engineering, 130(11),111301.

[8] Hakimi, N., 1998. "Preconditioning methods for time dependent Navier-Stokes equations", Ph.D. Thesis, Vrije University, Brussels, Belgium.

[9] Hakimi, N., Hirsch, C., and Pierret, S., 2000. "Presentation and application of a new extended k-e model with wall functions", ECCOMAS Symposium, Barcelona, Spain.

[10] Holl, JW., Billet, ML., and Weir, DS., 1975. "Thermodynamic effects on developed cavitation", Journal of Fluids Engineering, 507-514.

[11] Hord, J., 1974. "Cavitation in liquid Cryogens, Vol 4, combined correlations for Venturi, Hydrofoil, Ogives and Pumps", NASA CR-2448.

[12] Hosangadi, A., and Ahuja, V., 2005. "Numerical study of cavitation in cryogenic fluids", Journal of Fluids Engineering, 127:267-281.

[13] Hosangadi, A., and Ahuja, V., 2006. "Numerical study of a flat plate inducer: comparison of performance in liquid hydrogen and water", 6th Int. Symposium on Cavitation CAV2006, Wageningen, The Netherlands. 
[14] Jameson, A., Schmidt, W., and Turkel, E., 1981. "Numerical simulation of the Euler equations by finite volume method using Runge-Kutta time stepping schemes", AIAA paper 81-1259.

[15] Meng, P.R., and Moore, R.D., 1970. "Hydrogen cavitation performance of $80.6^{\circ}$ helical inducer mounted in line with stationary centerbody", NASA TN X-1935.

[16] Moore, R.D., and Ruggeri, R.S., 1968. "Prediction of thermodynamic effects on developed cavitation based on liquid hydrogen and freon 114 data in scaled venturis", NASA TN D-4899.

[17] Pouffary, B., Fortes-Patella, R., Reboud, J-L., and Lambert, P-A., 2008. "Numerical simulation of 3D cavitating flows: analysis of cavitation head drop in turbomachinery", Journal of Fluids Engineering, 130(4),041302.

[18] Rapposelli, E., and d'Agostino, L., 2003. "A barotropic cavitation model with thermodynamic effects", 5th Int. Symposium on Cavitation CAV2003, Osaka, Japan.

[19] Rolland, J., Fortes, R., Goncalves, E., Boitel, Barre, S., 2006. "Experiments and Modelling of Cavitating Flows in Venturi, Part I: Stable Cavitation", 5th Int. Symposium on Cavitation CAV2006, Wageningen, The Netherlands.

[20] Rolland, R., 2008. "Modélisation des écoulements cavitants dans les inducteurs de turbopompes: prise en compte des effets thermodynamiques", Ph.D. Thesis, Institut Polytechnique de Grenoble, France.

[21] Stahl, H.A., and Stepanoff, A.J., 1956. "Thermodynamic aspects of cavitation in centrifugal pumps", ASME Journal of Basic Engineering, 78:1691-1693. 
[22] Utturkar, Y., Wu, J., Wang, G., and Shyy, W., 2005. "Recent progress in modeling of cryogenic cavitation for liquid rocket propulsion", Progress in Aerospace Sciences, 41:558-608.

[23] Watanabe, S., Furukawa, A., and Yoshida, Y., 2008. "Theoretical analysis of thermodynamic effect of cavitation in cryogenic inducer using singularity method", Int. J. of Rotating Machinery, 2008,125678.

[24] Yang, Z., and Shih T.H., 1993. "A $k-\varepsilon$ model for tubulence and transitional boundary layer", Near-wall Turbulent Flows, R.M.C. So., C.G. Speziale and B.E. Launder (Editors), Elsevier-Science Publishers B. V., pp.165-175.

[25] Zhang, X.B., Qiu, L.M., Gao, Y., and Zhang, X.J., 2008. "Computational fluid dynamic study on cavitation in liquid nitrogen", Cryogenics, 48:432-438. 


\section{List of Figure Captions}

1. Figure 1: view of the inducer

2. Figure 2: view of the blade leading edge

3. Figure 3: view of the mesh

4. Figure 4: head drop chart, computations versus experiments

5. Figure 5: contour of void ratio $\alpha=0.1, \phi=0.108$ and $T_{r e f}=23 \mathrm{~K}$

6. Figure 6: meridian view, cutting plane

7. Figure 7: void ratio on a mid-span cut, blade-to-blade view, $\phi=0.108, T_{r e f}=23 \mathrm{~K}$

8. Figure 8: temperature on a mid-span cut, blade-to-blade view, $\phi=0.108, T_{\text {ref }}=23 \mathrm{~K}$

9. Figure 9: void ratio on a near-shroud cut, blade-to-blade view, $\phi=0.108, T_{\text {ref }}=23 \mathrm{~K}$

10. Figure 10: void ratio on a near-shroud cut, blade-to-blade view, $\phi=0.098, T_{r e f}=19 \mathrm{~K}$

11. Figure 11: temperature on a near-shroud cut, blade-to-blade view, $\phi=0.108, T_{r e f}=$ $23 \mathrm{~K}$

12. Figure 12: wall temperature on suction side, $\phi=0.108, T_{\text {ref }}=23 \mathrm{~K}$

13. Figure 13: wall temperature on suction side in cavitating conditions

14. Figure 14: wall temperature on pressure side in cavitating conditions

15. Figure 15: wall temperature on suction side, $\phi=0.098, T_{r e f}=19 \mathrm{~K}$ 
16. Figure 16: wall heat transfer on suction side, $\phi=0.108, T_{r e f}=23 \mathrm{~K}$

17. Figure 17: view of meshes: coarse (left) and fine (right)

18. Figure 18: wall temperature on suction side, $\phi=0.103, T_{r e f}=22 \mathrm{~K}$, fine mesh 


\begin{tabular}{llll}
\hline temperature $(\mathrm{K})$ & 19 & 21 & 23 \\
\hline vap. pressure $(\mathrm{Pa})$ & 67960 & 124720 & 209320 \\
$L_{\text {vap }}(\mathrm{kJ} / \mathrm{kg})$ & 449.9 & 441.84 & 427.27 \\
$\rho_{L}\left(\mathrm{~kg} / \mathrm{m}^{3}\right)$ & 72.2 & 70.0 & 67.4 \\
$\rho_{V}\left(\mathrm{~kg} / \mathrm{m}^{3}\right)$ & 0.94 & 1.62 & 2.60 \\
$C_{p_{L}}(\mathrm{~J} / \mathrm{kg} . \mathrm{K})$ & 8840 & 10150 & 11672 \\
$\frac{d P_{\text {vap }}}{d T}(\mathrm{~Pa} / \mathrm{K})$ & 22280 & 35300 & 50000 \\
$\Delta T^{*}(\mathrm{~K})$ & 0.66 & 1.01 & 1.41 \\
$\Delta P^{*}(\mathrm{~Pa})$ & 14705 & 35653 & 70500 \\
\hline
\end{tabular}

Table 1: THERMODYNAMICS PROPERTIES OF HYDROGEN AT SATURATION. 


\begin{tabular}{llll} 
temperature $(\mathrm{K})$ & 19 & 23 & 23 \\
\hline$U_{\text {ref }}=R \omega(\mathrm{m} / \mathrm{s})$ & 200 & 200 (shroud) & 165 (hub) \\
$L_{\text {vap }}(\mathrm{kJ} / \mathrm{kg})$ & 449.9 & 427.27 & 427.27 \\
Eckert number & 0.089 & 0.093 & 0.064 \\
Mach number & 0.17 & 0.2 & 0.17 \\
$\rho_{L} U_{\text {ref }}^{2} / \Delta P^{*}$ & 196.4 & 38.2 & 26 \\
\hline
\end{tabular}

Table 2: DIMENSIONLESS PARAMETERS AT DIFFERENT REFERENCE TEMPERATURE. 


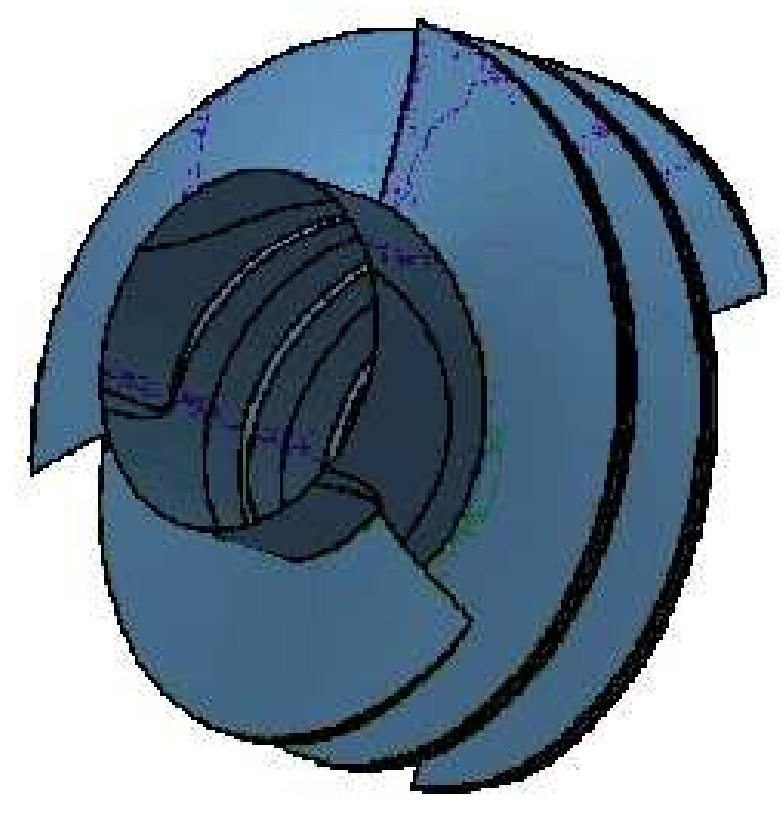

Figure 1: VIEW OF THE INDUCER. 


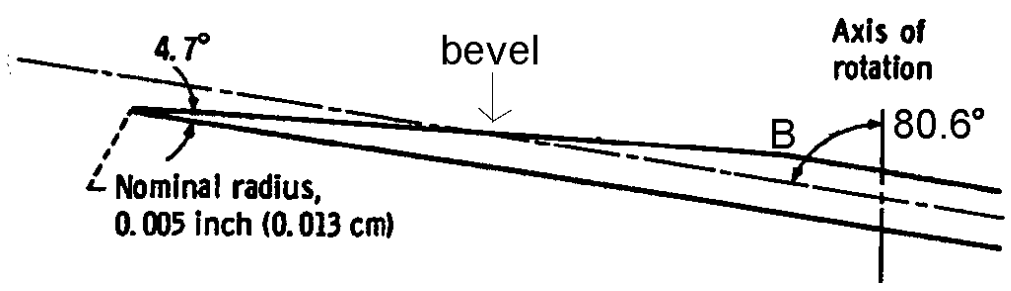

Figure 2: VIEW OF THE BLADE LEADING EDGE [15]. 


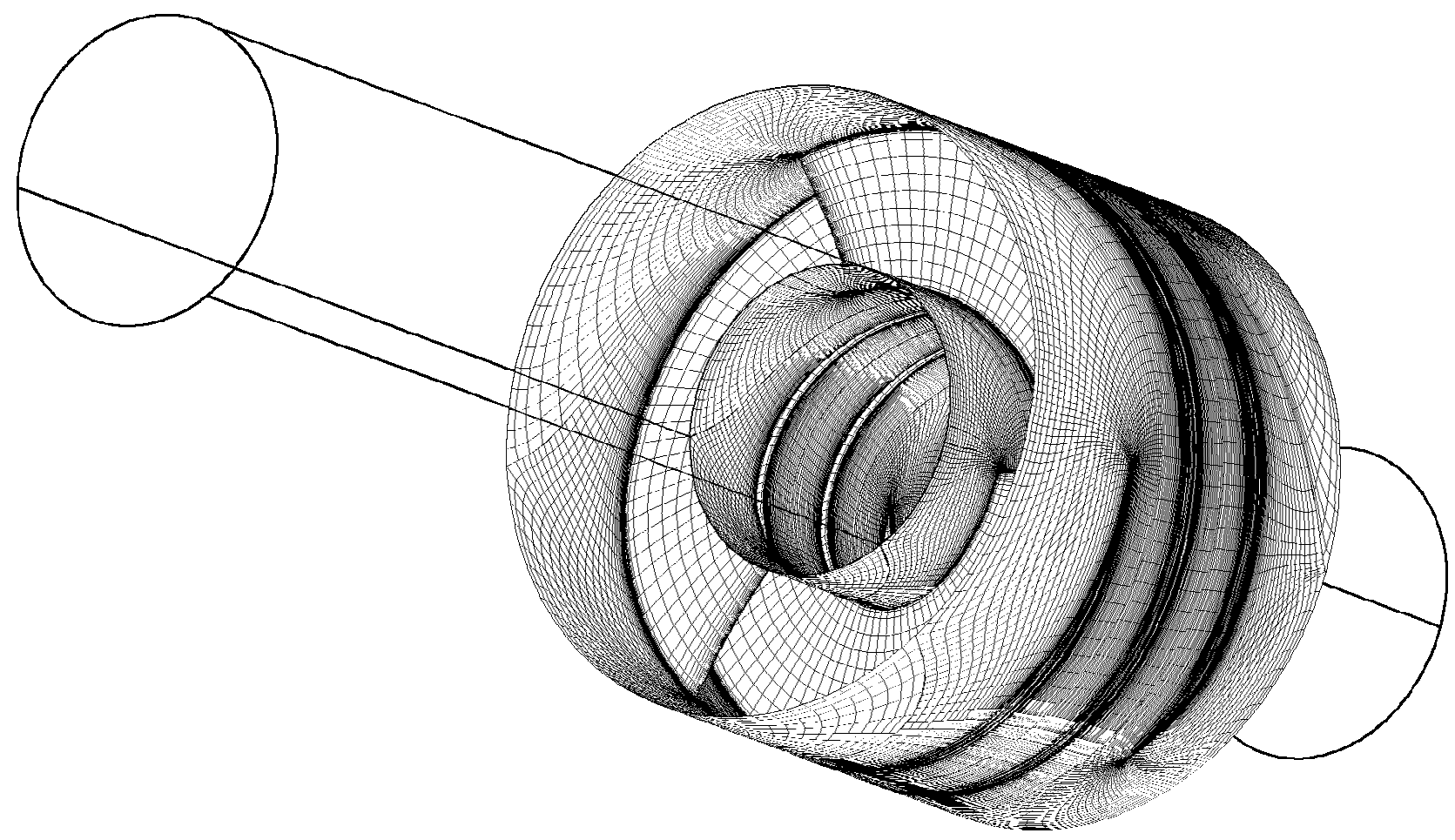

Figure 3: VIEW OF THE MESH. 


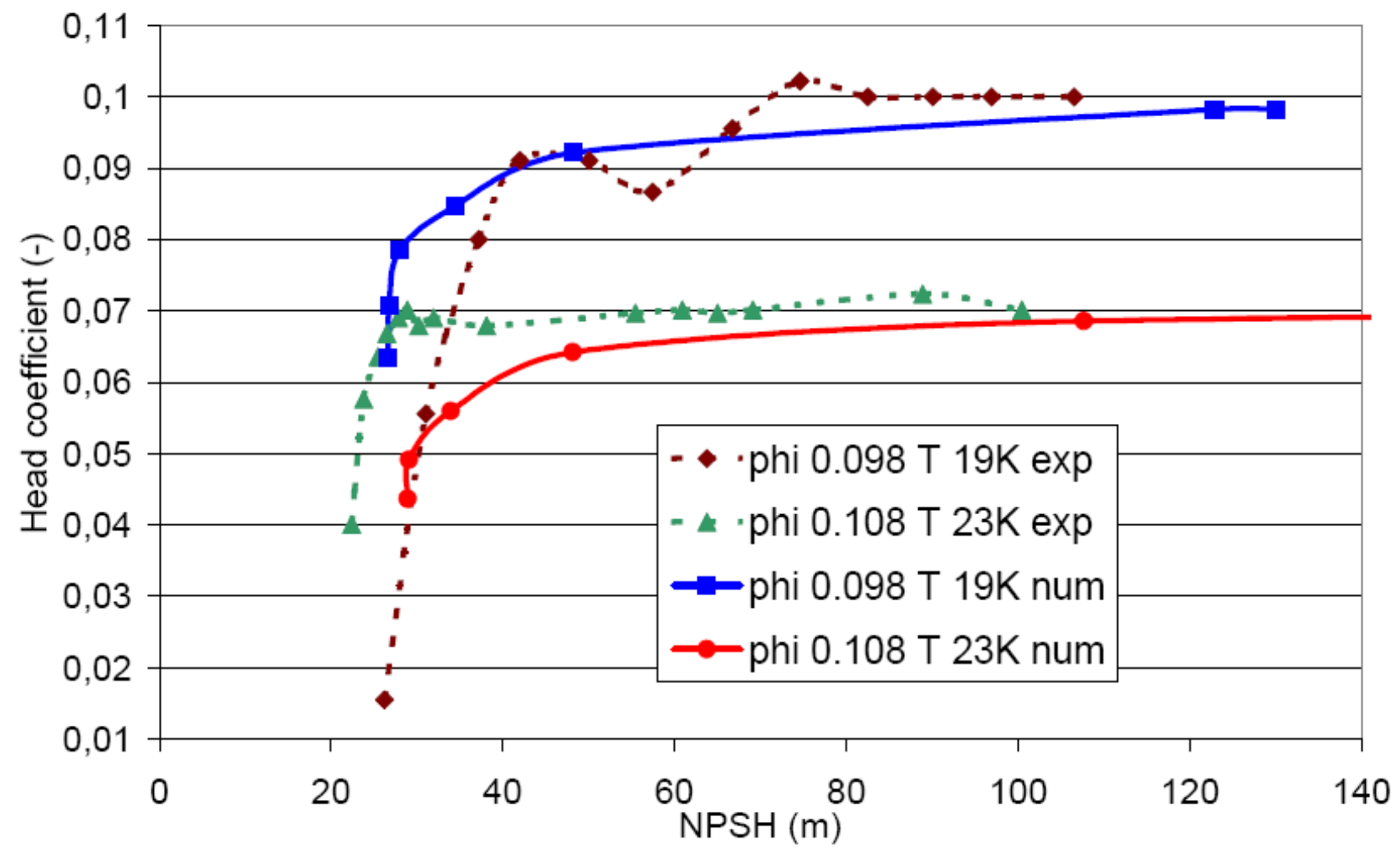

Figure 4: HEAD DROP CHART, COMPUTATIONS VERSUS EXPERIMENTS. 


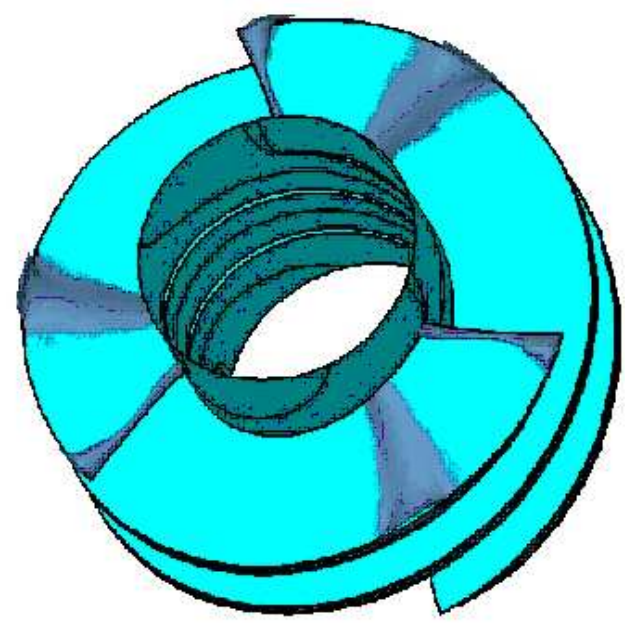

$\mathrm{NPSH}=108 \mathrm{~m}$

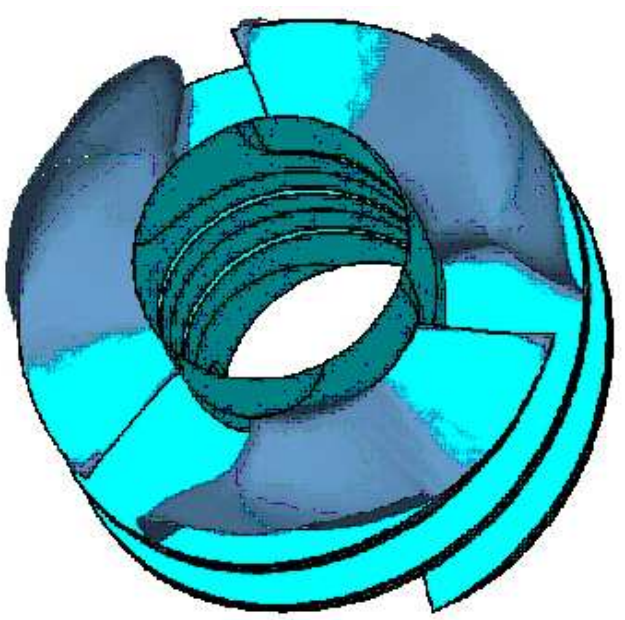

$\mathrm{NPSH}=48 \mathrm{~m}$

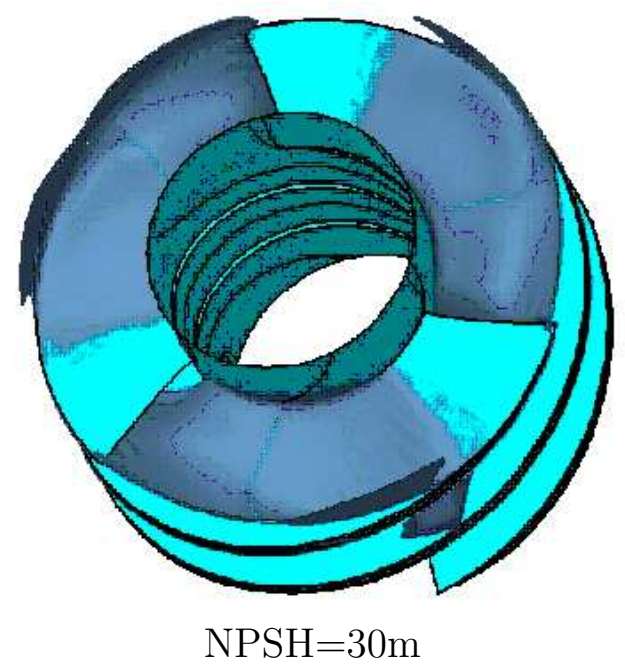

Figure 5: CONTOUR OF VOID RATIO $\alpha=0.1, \phi=0.108, T_{r e f}=23 \mathrm{~K}$. 


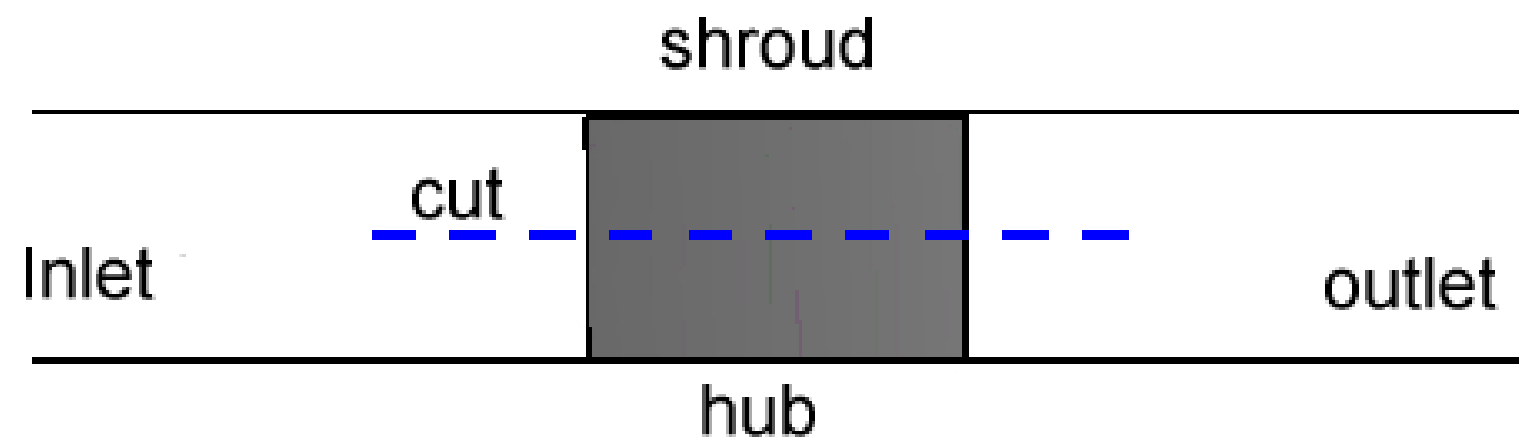

Figure 6: MERIDIAN VIEW, CUTTING PLANE 


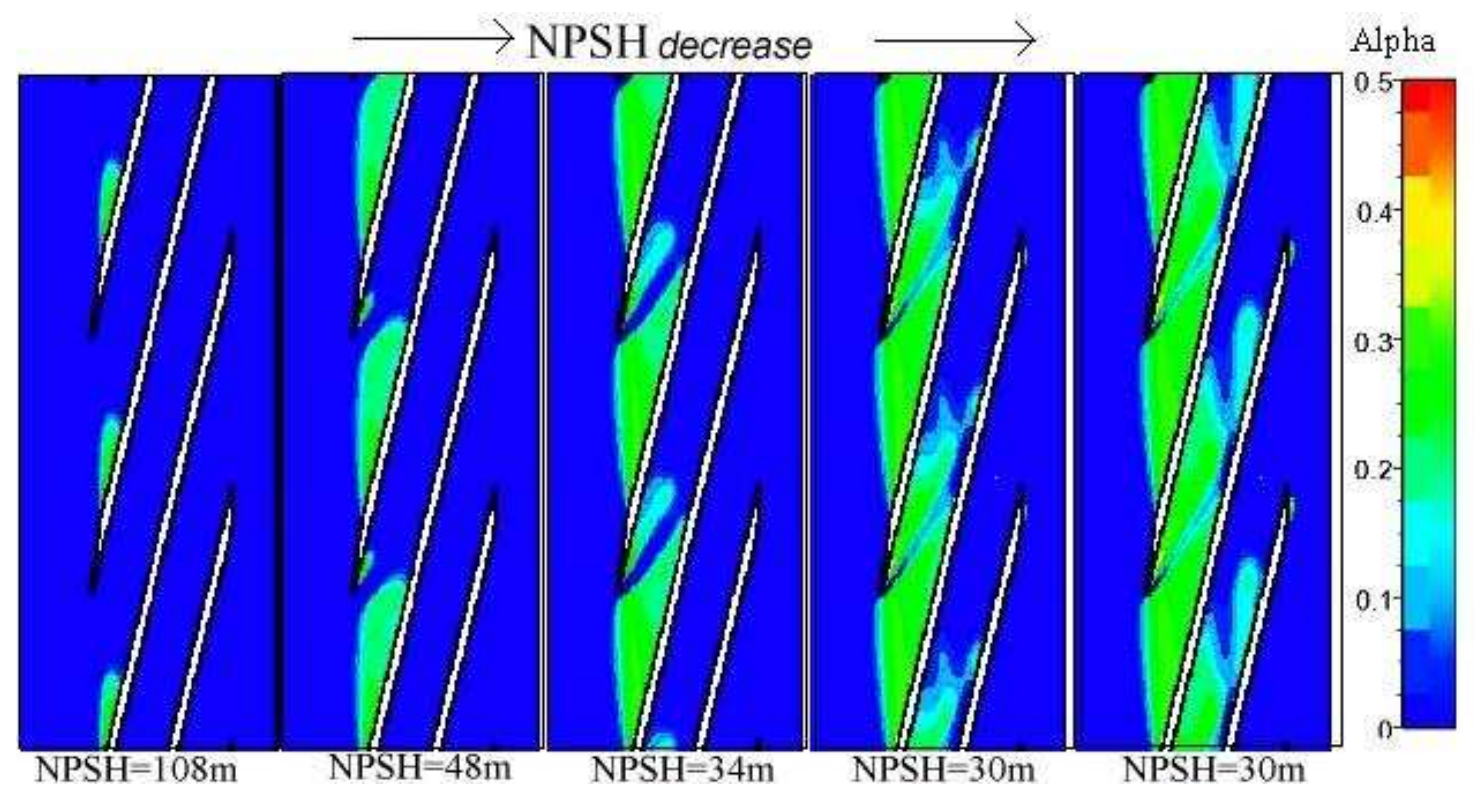

Figure 7: VOID RATIO ON A MID-SPAN CUT, BLADE-TO-BLADE VIEW, $\phi=0.108$, $T_{\text {ref }}=23 \mathrm{~K}$. 


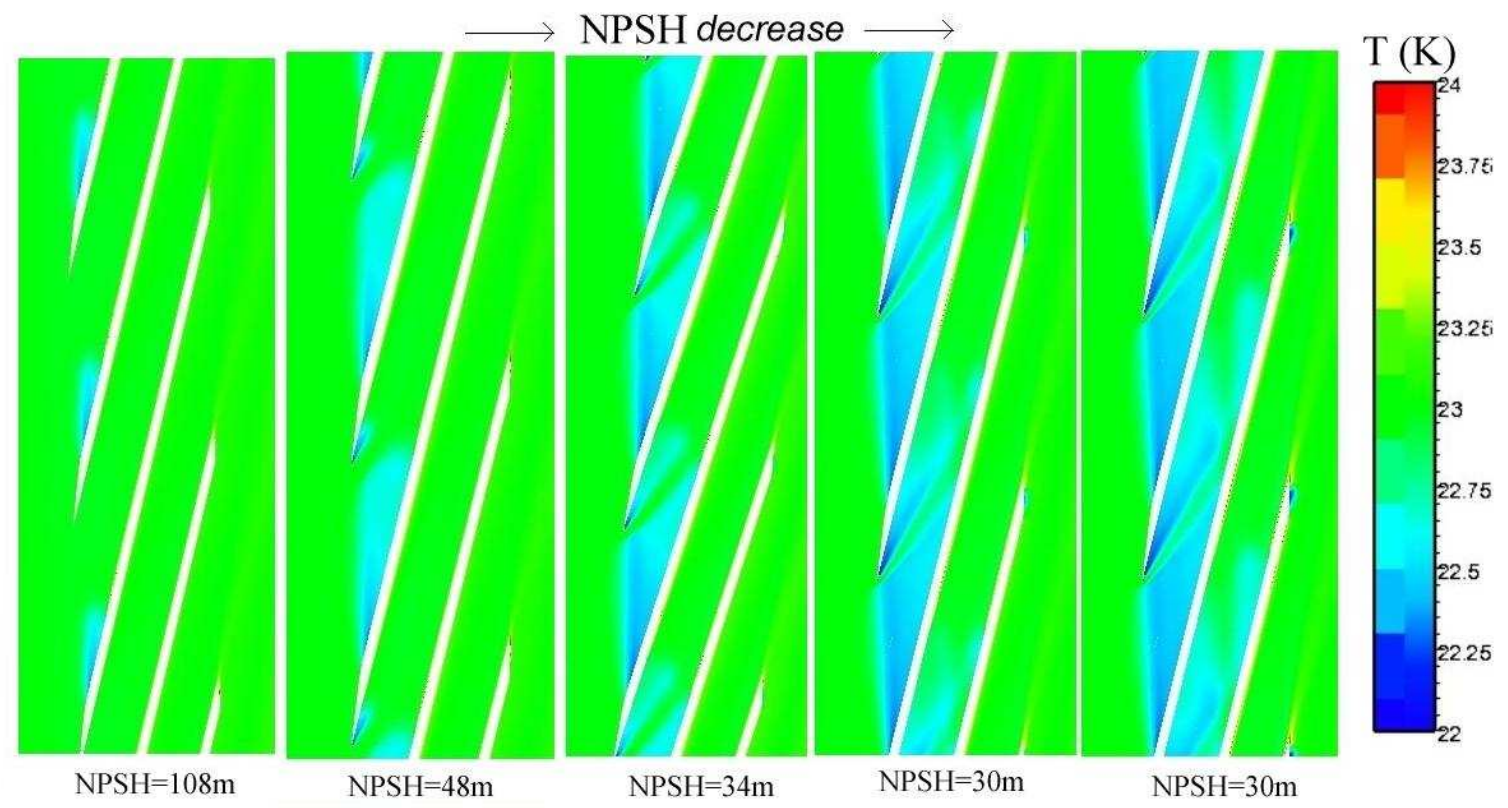

Figure 8: TEMPERATURE ON A MID-SPAN CUT, BLADE-TO-BLADE VIEW, $\phi=0.108$, $T_{\text {ref }}=23 \mathrm{~K}$. 


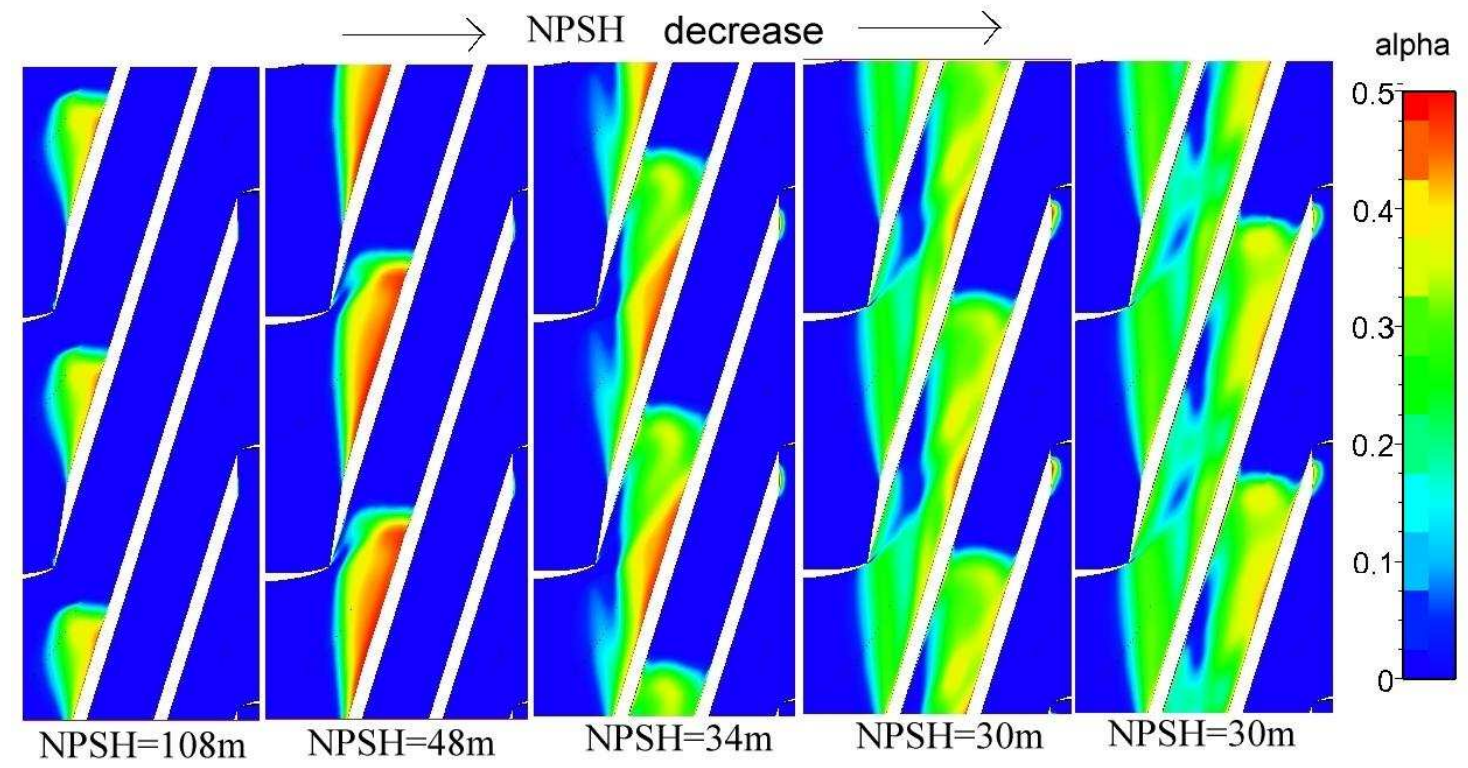

Figure 9: VOID RATIO ON A NEAR-SHROUD CUT, BLADE-TO-BLADE VIEW, $\phi=0.108, T_{\text {ref }}=23 \mathrm{~K}$. 


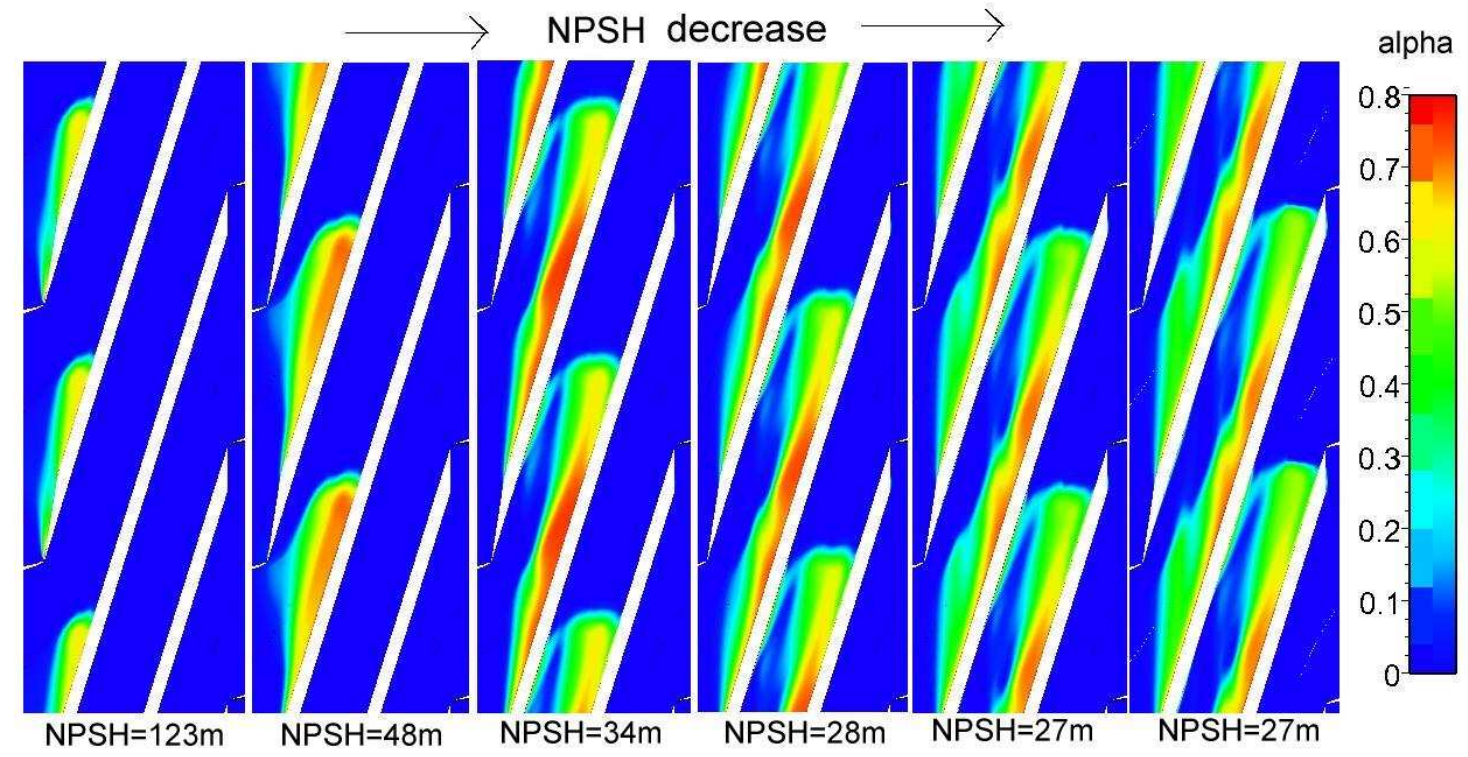

Figure 10: VOID RATIO ON A NEAR-SHROUD CUT, BLADE-TO-BLADE VIEW, $\phi=0.098, T_{r e f}=19 \mathrm{~K}$. 


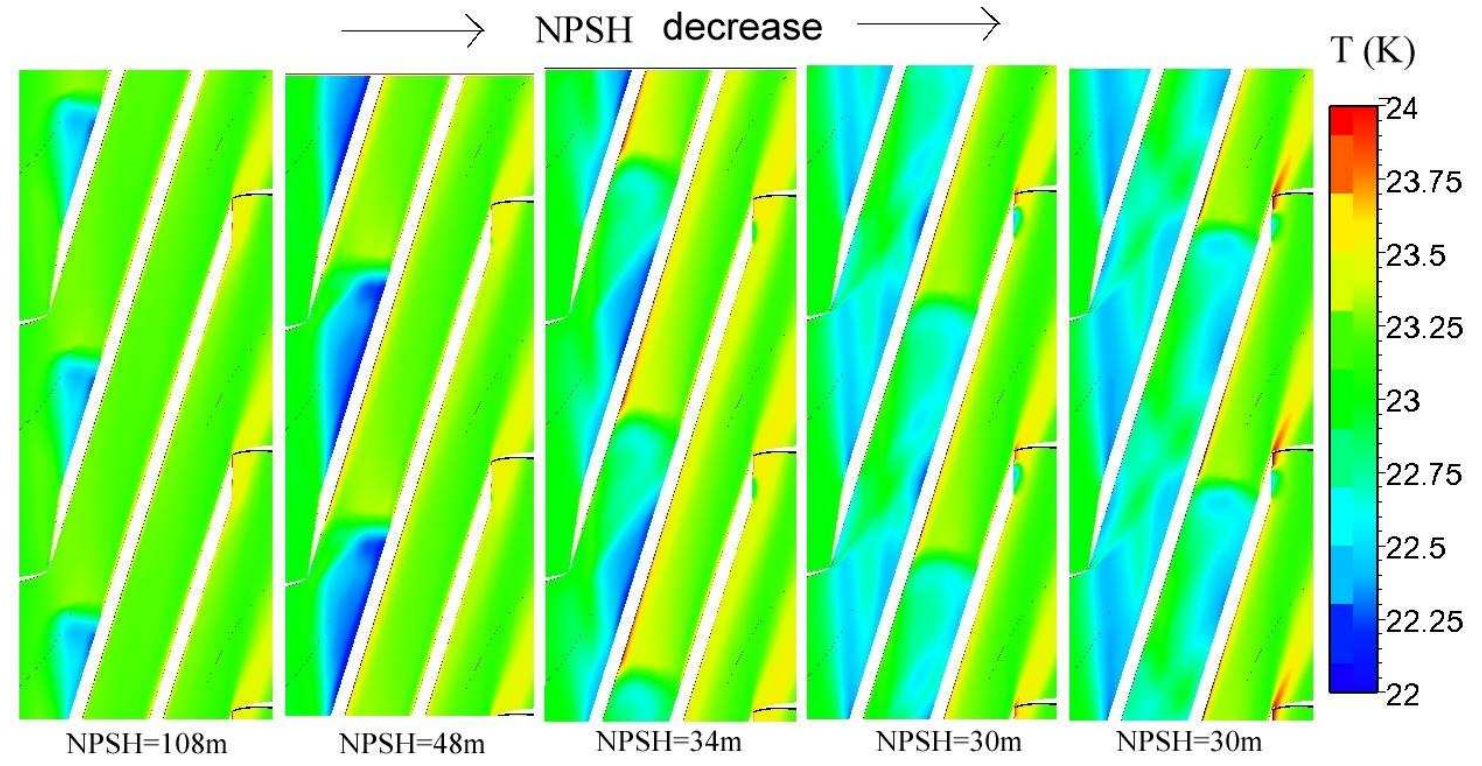

Figure 11: TEMPERATURE ON A NEAR-SHROUD CUT, BLADE-TO-BLADE VIEW, $\phi=0.108, T_{\text {ref }}=23 \mathrm{~K}$. 

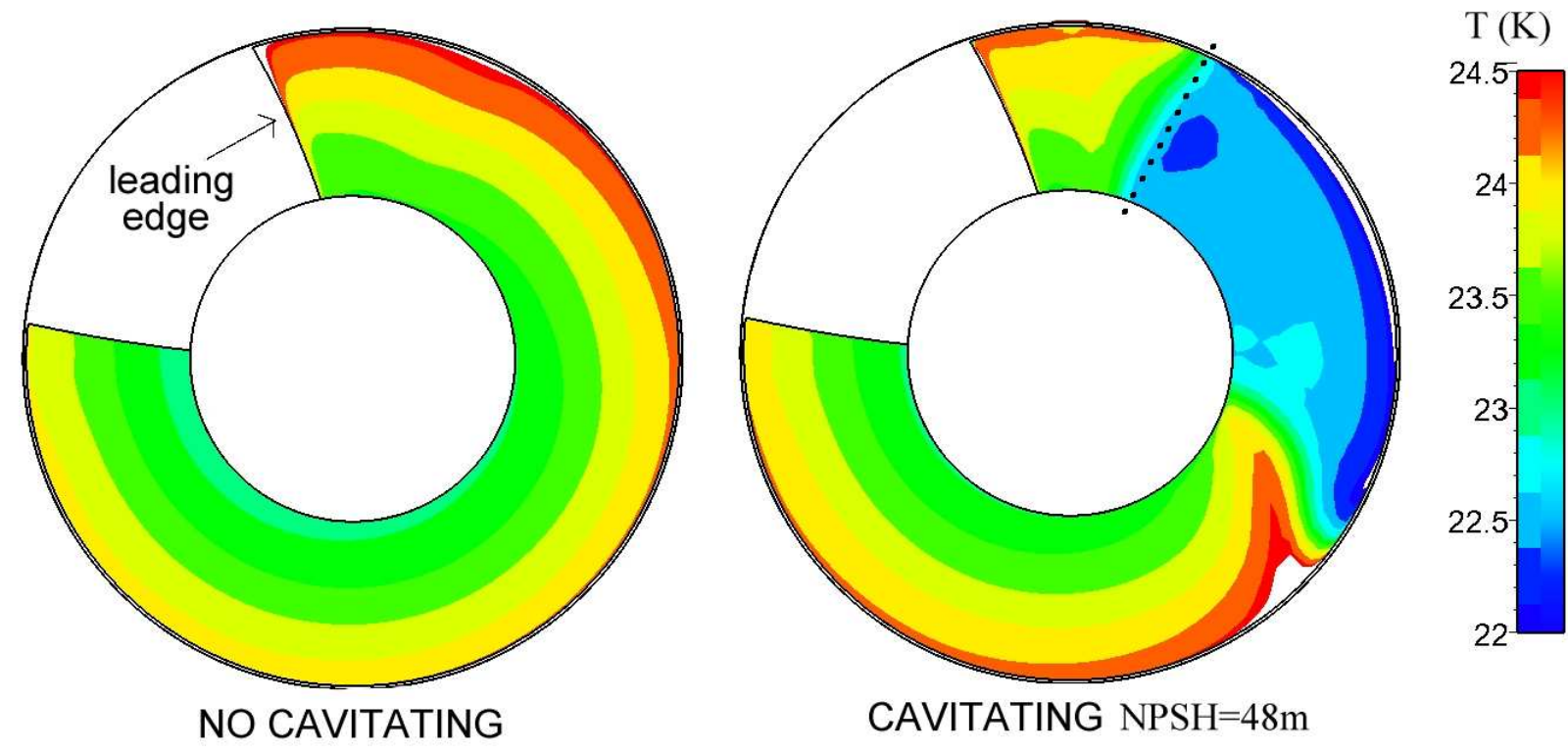

Figure 12: WALL TEMPERATURE ON SUCTION SIDE, $\phi=0.108, T_{r e f}=23 \mathrm{~K}$. 


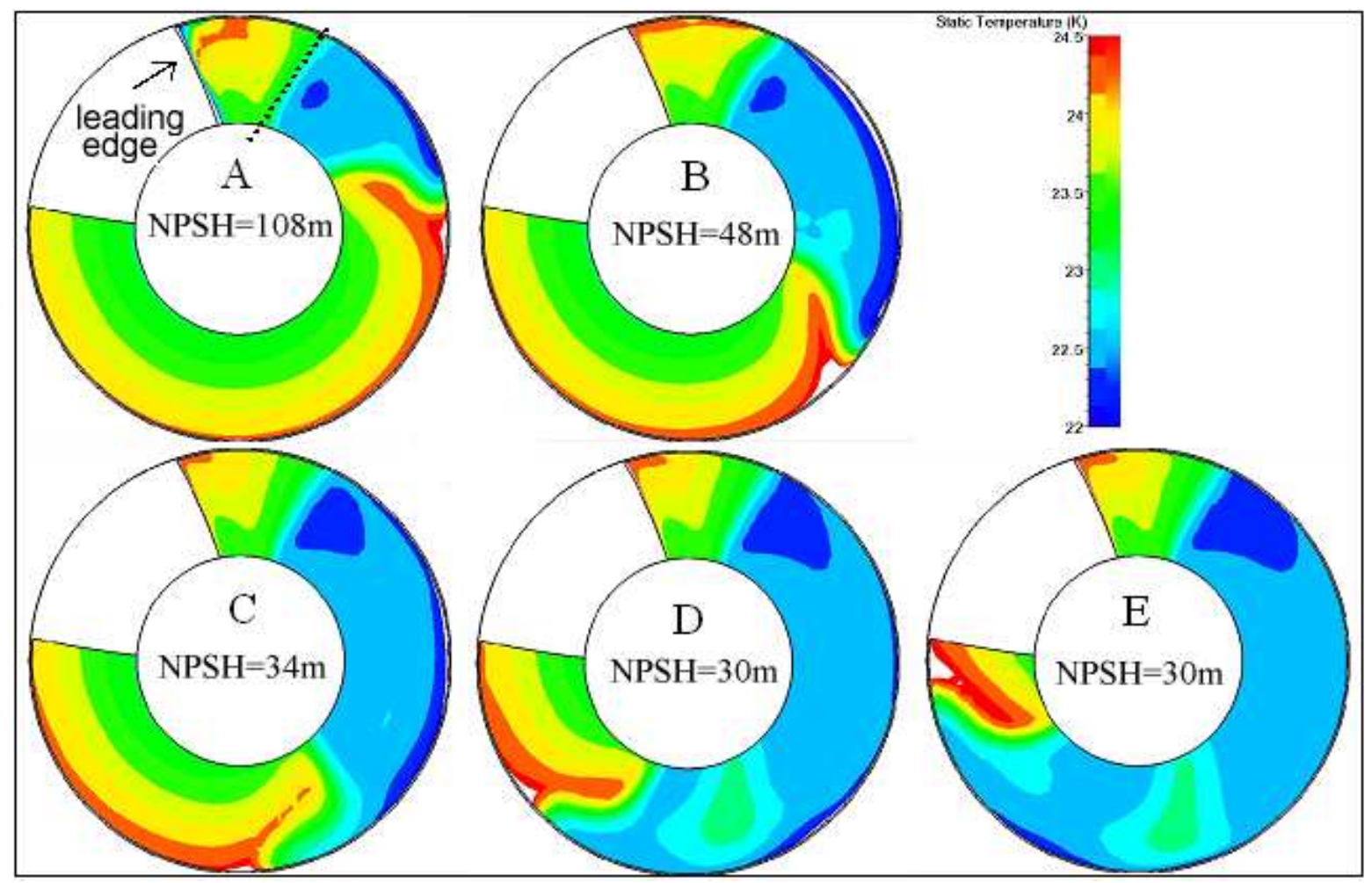

Figure 13: WALL TEMPERATURE ON SUCTION SIDE IN CAVITATING CONDITIONS. 


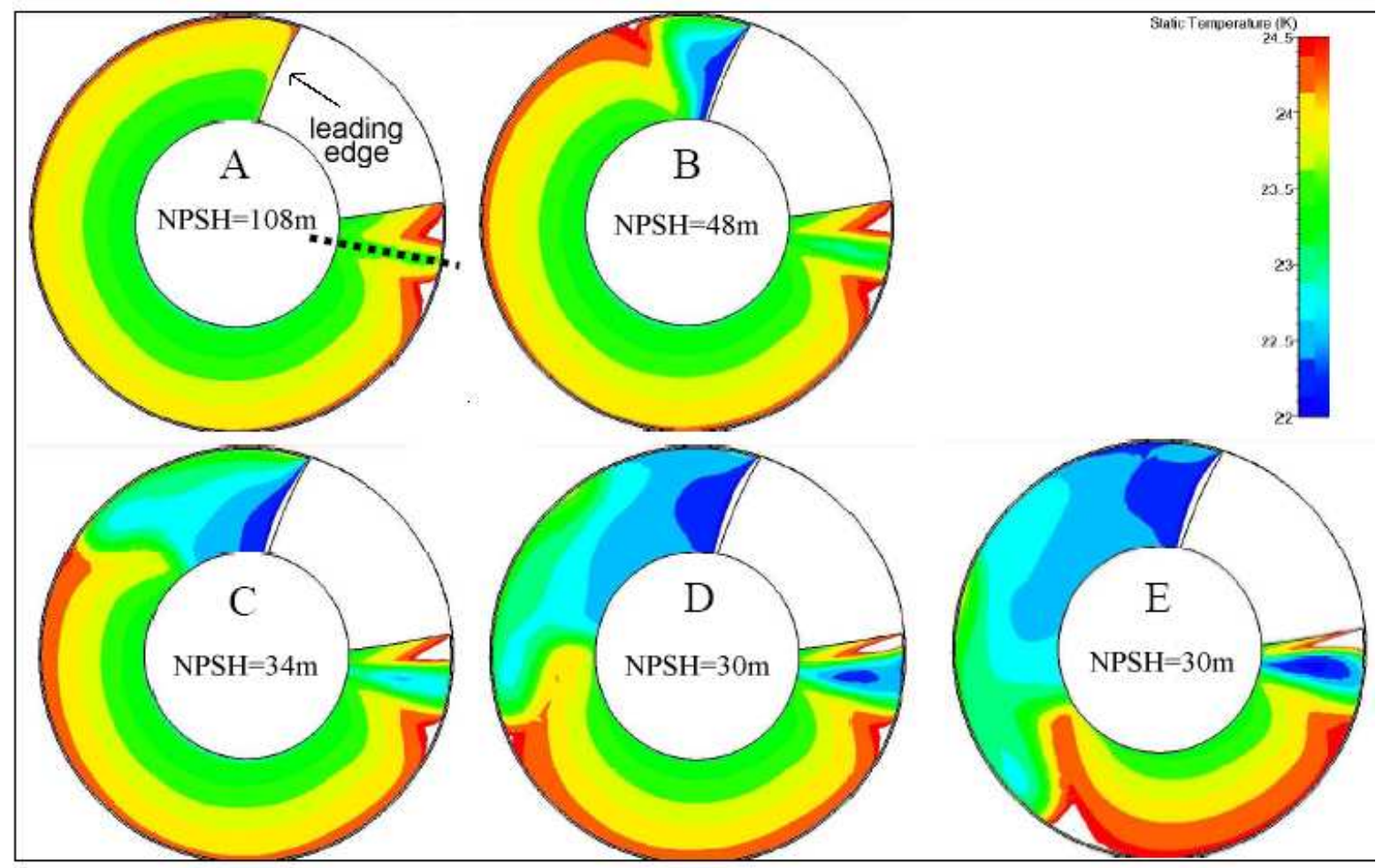

Figure 14: WALL TEMPERATURE ON PRESSURE SIDE IN CAVITATING CONDITIONS. 

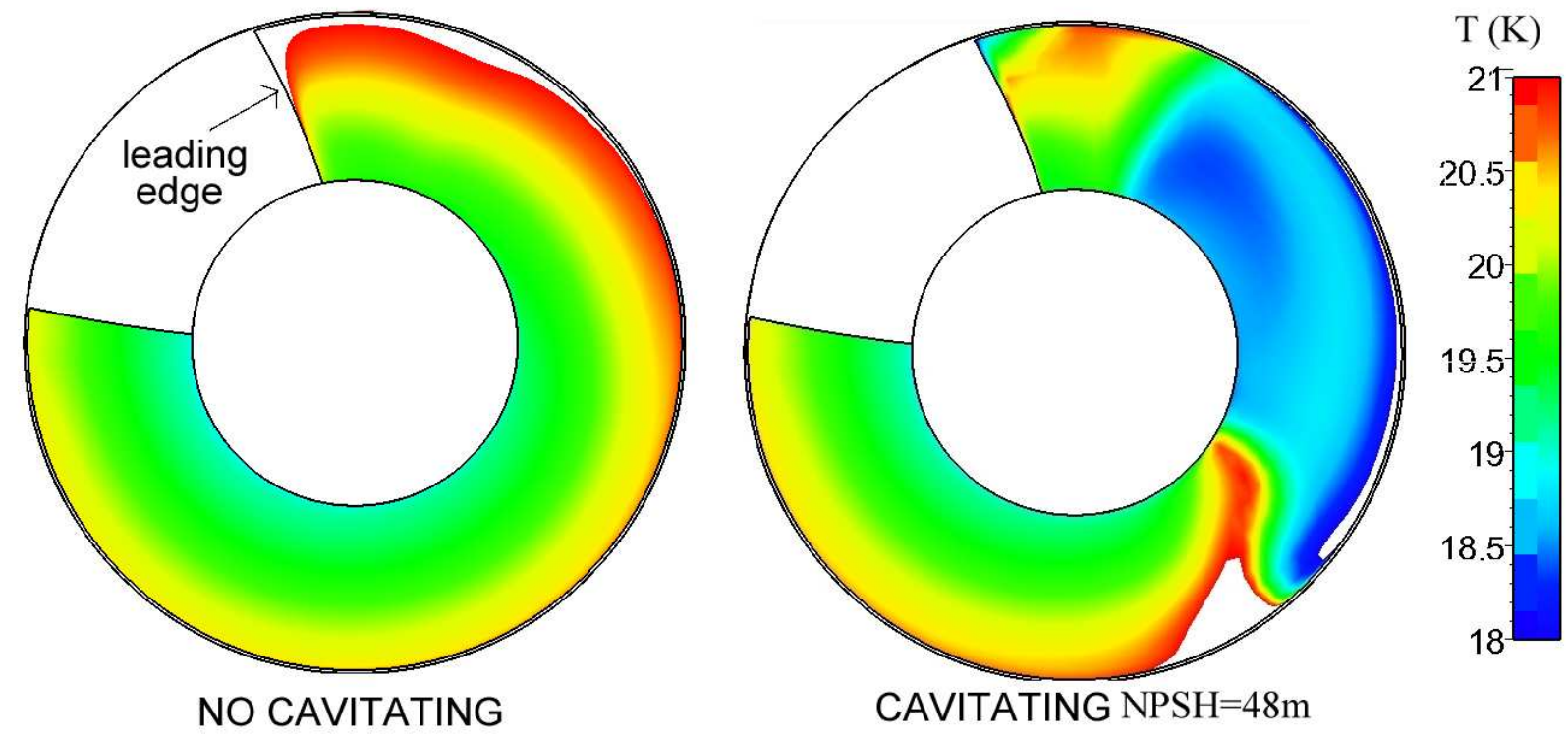

Figure 15: WALL TEMPERATURE ON SUCTION SIDE, $\phi=0.098, T_{r e f}=19 \mathrm{~K}$. 

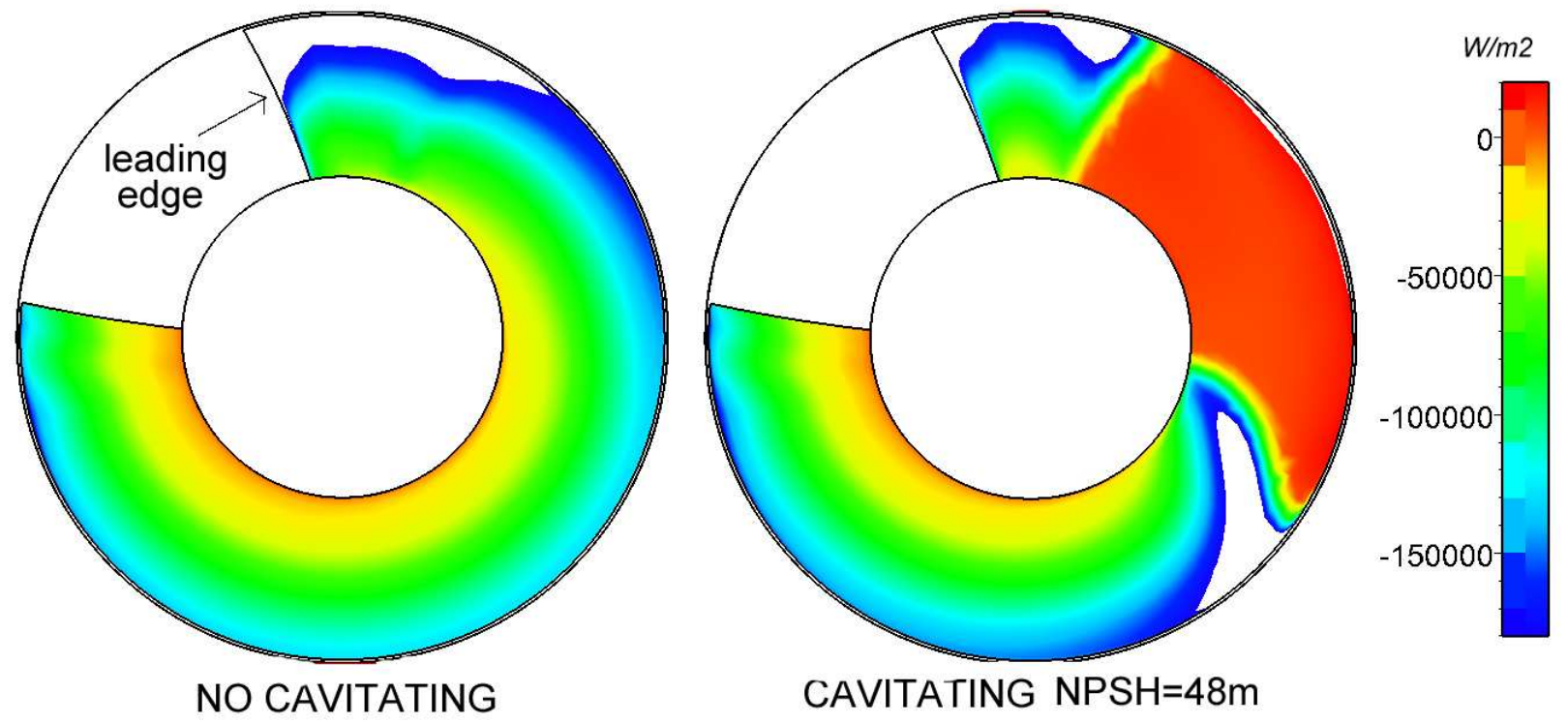

Figure 16: WALL HEAT TRANSFER ON SUCTION SIDE, $\phi=0.108, T_{r e f}=23 \mathrm{~K}$. 

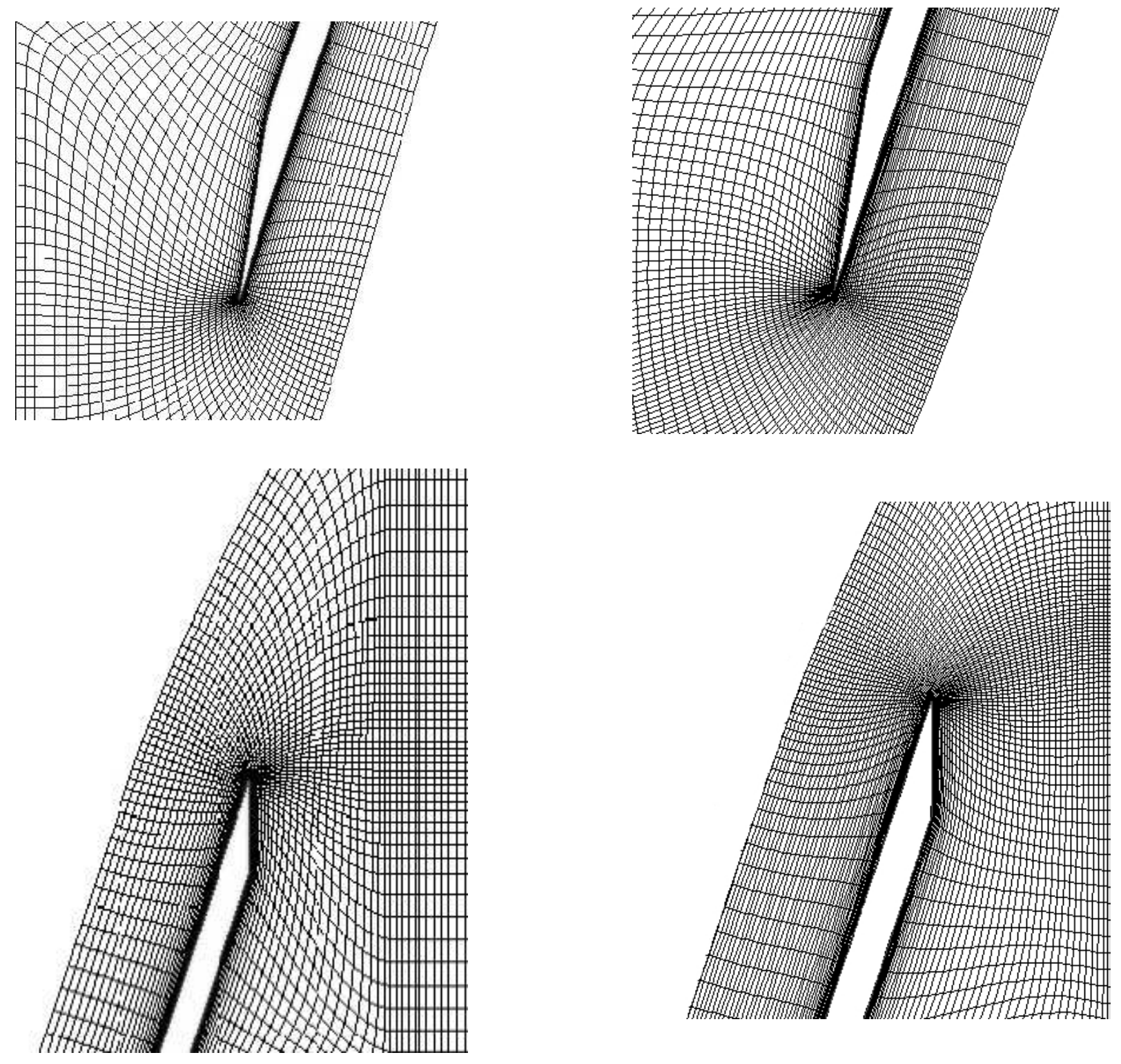

Figure 17: VIEW OF MESHES: COARSE (LEFT) AND FINE (RIGHT). 

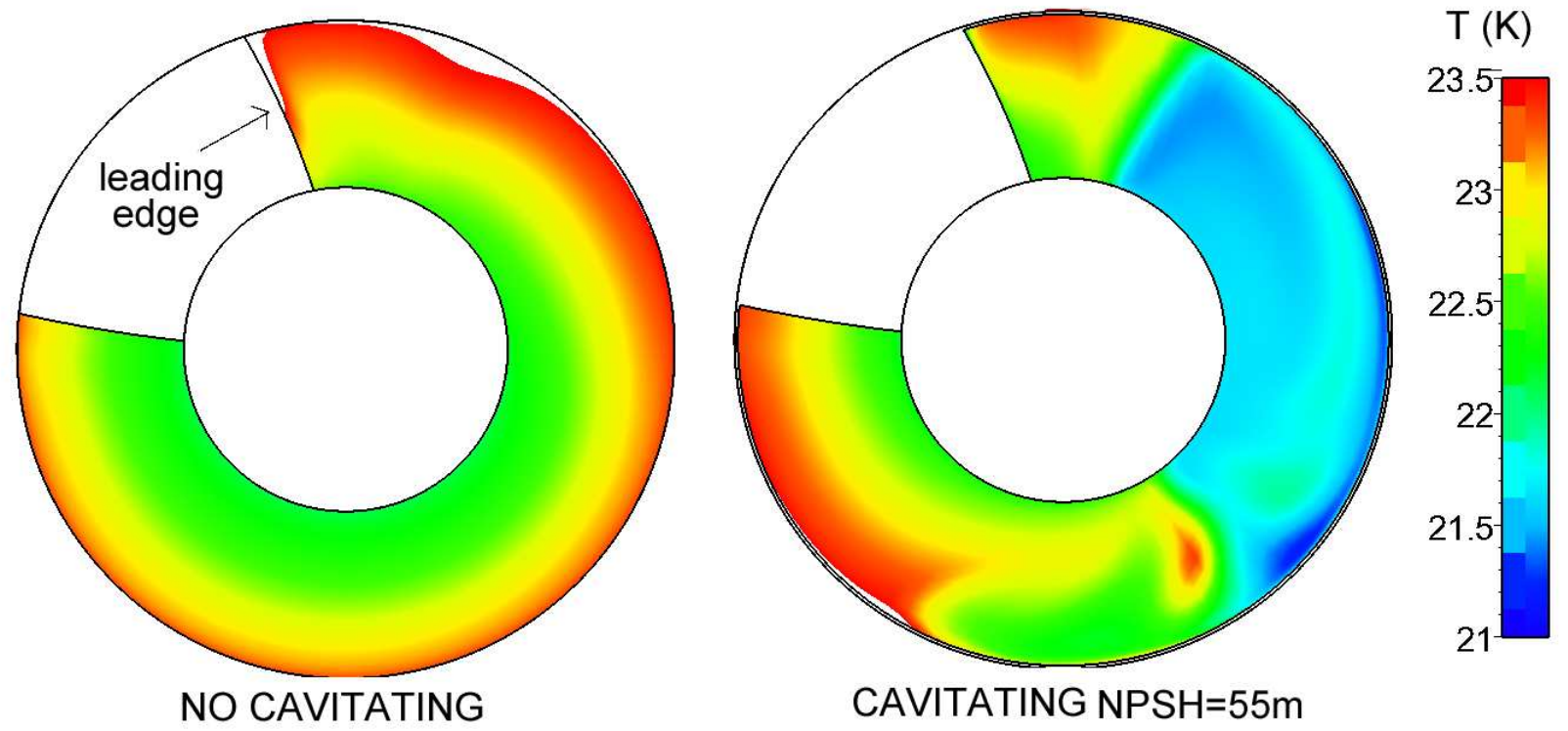

Figure 18: WALL TEMPERATURE ON SUCTION SIDE, $\phi=0.103, T_{r e f}=22 \mathrm{~K}$, FINE MESH. 